\begin{tabular}{ccc} 
Tersedia online di: http://ejournal-balitbang.kkp.go.id/index.php/jppi & JURNAL \\
P-mail:jppi.puslitbangkan @ gmail.com & PENELITIN \\
PERIKANAN & IDDONESIA \\
JURNALPENELITIANPERIKANANINDONESIA & Volume 22 Nomor 4 Desember 2016 \\
p-ISSN: 0853-5884 & e-ISSN: 2502-6542 \\
\hline Nomor Akreditasi: 653/AU3/P2MI-LIPI/07/2015
\end{tabular}

\title{
PENGARUH FASE BULAN TERHADAP WAKTU TEBAR PANCING DAN LAJU TANGKAP MADIDIHANG (Thunnus albacares Bonnaterre, 1788) PADA ARMADA RAWAI TUNA
}

\section{THE EFFECTS OF MOON PHASE TO SET TIME AND CATCH OF YELLOWFIN TUNA (Thunnus albacares Bonnaterre, 1788) ON TUNA LONGLINE VESSEL}

\author{
Irwan Jatmiko*1, Bram Setyadji dan Arief Wujdi ${ }^{1}$ \\ ${ }^{1}$ Loka Penelitian Perikanan Tuna, Jl. Mertasari, No.140, Sidakarya, Denpasar, Bali 80224, Indonesia \\ Teregistrasi I tanggal: 28 November 2016; Diterima setelah perbaikan tanggal: 15 Desember 2016; \\ Disetujui terbit tanggal: 16 Desember 2016
}

\begin{abstract}
ABSTRAK
Madidihang merupakan salah satu jenis ikan tuna ekonomis penting bagi industri perikanan di Indonesia dengan kontribusi hasil tangkapan yang terbanyak. Penelitian ini bertujuan untuk mengetahui pengaruh fase bulan terhadap waktu mulai tebar pancing dan laju tangkap madidihang pada armada rawai tuna. Pengumpulan data dilakukan oleh pemantau ilmiah pada armada rawai tuna yang sebagian besar berbasis di Pelabuhan Benoa, Bali mulai Agustus 2005 hingga Juni 2014. Daerah penangkapan ikan dari armada rawai tuna yang diambil datanya berada di lokasi (lintang dan bujur) $9^{\circ}-16^{\circ}$ LS hingga $109^{\circ}-120^{\circ}$ BT. Analisis anova satu arah dan tes Tukey dilakukan untuk mengetahui pengaruh fase bulan terhadap waktu mulai tebar pancing dan laju tangkap madidihang. Total sebanyak 60 trip dan 1.467 hari operasi penangkapan armada rawai tuna dilakukan dalam penelitian ini. Analisis statistik anova satu arah menunjukkan bahwa terdapat pengaruh yang nyata pada fase bulan terhadap waktu mulai tebar pancing $(p<0,05)$. Selanjutnya, tes Tukey menunjukkan bahwa waktu mulai tebar pancing pada saat bulan purnama dimulai pada pukul 9:00 pagi hari. Waktu ini lebih lambat sekitar 2 jam dari pada waktu mulai tebar pancing pada ketiga fase bulan lainnya (perbani awal, perbani akhir dan bulan baru) yang dilakukan sekitar pukul 7:00 pagi hari. Analisis statistik anova satu arah juga menunjukkan terdapat perbedaan yang nyata antar fase bulan terhadap laju tangkap madidihang $(p<0,05)$. Selanjutnya, tes Tukey menunjukkan bahwa laju tangkap pada saat bulan baru dan perbani awal sebesar 0,13 ekor/100 mata pancing atau lebih besar dibandingkan nilai laju tangkap pada saat purnama dan perbani akhir yang hanya sebesar 0,09 ekor/100 mata pancing.
\end{abstract}

Kata Kunci: Waktu tebar pancing; hasil tangkapan; fase bulan; madidihang; rawai tuna

\begin{abstract}
Yellowfin tuna is one of the most economically important species for fisheries industry in Indonesia. The objectives of this study are to investigate the effect of lunar phase to the set time start and catch rate of yellowfin tuna on tuna longline vessels. Data collected by scientific observer on tuna longline vessels mainly based in Benoa Port, Bali from August 2005 to June 2014. Fishing ground of sampled longline tuna located from $9^{\circ}-16^{\circ} \mathrm{S}$ to $109^{\circ}-120^{\circ} \mathrm{E}$. One-way anova analysis and Tukey test conducted to examine the effect of lunar phase to the set time start and catch rate of yellowfin tuna. A total of 60 trips and 1,467 fishing days of longline tuna fishing vessels operation have been sampled for in this study. One-way anova analysis showed that there was a significant difference of lunar phase to the set time start $(p<0.05)$. Furthermore, Tukey test showed that the starting time for setting during the full moon begins at 9:00 am. Its time was around 2 hours slower than the start of setting of the other three moon phase (first quarter, last quarter and new moon) which start around 7:00 am. One-way anova analysis also showed that there was a significant
\end{abstract}


difference of lunar phase to catch rate of yellowfin tuna $(p<0.05)$. Furthermore, Tukey test confirmed that hook rate on new moon and first quarter was $0.13 / 100$ hooks or 0.4 bigger than hook rate on full moon and last quarter with only 0.09/100 hooks.

Keywords: Set time; catch; Iunar phase; yellowfin tuna; tuna longline

\section{PENDAHULUAN}

Rawai tuna merupakan alat tangkap dominan untuk menangkap tuna yang didaratkan di Pelabuhan Benoa, Bali (Nugraha \& Setyadji, 2013). Agar operasi penangkapan rawai tuna berjalan efektif dan efisien diperlukan teknik penangkapan yang tepat (Hamilton et al., 2011; Soepriyono, 2009). Hal ini diperlukan agar operasi pengkapan dapat berjalan efektif dan efisien, serta memperoleh hasil tangkapan secara optimal (FAO, 2012). Salah satu teknik yang digunakan adalah menentukan waktu mulai tebar pancing untuk mendapatkan hasil tangkapan yang optimal. Salah satu ikan target armada rawai tuna adalah madidihang ( Thunnus albacares) yang mempunyai nilai ekonomis yang tinggi (Sadiyah \& Prisantoso, 2011).

Pada kurun waktu 2005-2012, produksi madidihang merupakan hasil tangkapan dominan yaitu sebesar $72 \%$ dari total tangkapan kelompok tuna besar yang mencapai 1,3 juta ton (DJPT, 2014). Ikan ini merupakan salah satu spesies tuna yang menjelajah lintas Samudra. Penyebaran spesies ini mulai dari perairan tropis hingga perairan subtropis. Spesies madidihang ini dapat ditemukan di tiga Samudra besar dunia yaitu Samudera Atlantik, Samudra Hindia dan Samudra Pasifik (Lehodey, 2001; Collette \& Nauen, 1983). Di Indonesia, penyebaran madidihang berada di perairan Samudra Hindia barat Sumatera dan selatan Jawa, Selat Makasar, Laut Flores, Laut Banda, Teluk Tomini, Laut Seram, Laut Sulawesi dan Samudra Pasifik utara Papua (Wudianto \& Nikijuluw, 2004).

Fase bulan diketahui mempengaruhi tingkah laku ikan dalam mencari makan, melakukan migrasi dan periode pemijahan (Das et al., 2015; King, 2010). Beberapa penelitian telah dilakukan untuk mengetahui pengaruh fase bulan terhadap hasil tangkapan ikan beberapa tahun terakhir. Akyol (2013) menyebutkan bahwa fase bulan mempengaruhi hasil tangkapan ikan pelagis di Laut Aegean, Turki. Selain itu, fase bulan juga mempengaruhi hasil tangkapan tuna pada perikanan huhate di Perairan Barat Daya India (Mohan \& Kunjikoya, 1987).

Secara umum, operasi penangkapan rawai tuna di Indonesia dimulai dengan tebar pancing (setting) yang umumnya dilakukan pada pagi hingga siang hari. Kemudian dilanjutkan dengan waktu perendaman (soaking time) pada sore hari dan diakhiri dengan tarik pancing (hauling) yang biasa dilakukan sepanjang malam hingga dini hari (Jatmiko et al., 2015). Jadi meskipun waktu tebar pancing dilakukan pada pagi dan siang hari, namun proses ikan memakan umpan dapat terjadi sepanjang hari hingga malam hari. Oleh karena itu, dalam beberapa penelitian, fase bulan diindikasikan mempunyai pengaruh terhadap hasil tangkapan ikan pada operasi penangkapan rawai tuna (Poisson et al., 2010; Sajeevan \& Rajashree, 2012)

Penelitian ini bertujuan untuk mengetahui pengaruh fase bulan terhadap waktu mulai tebar pancing dan laju tangkap madidihang ( $T$. albacares) pada armada rawai tuna di Samudra Hindia. Hasil penelitian ini diharapkan dapat memberikan informasi yang lebih lengkap tentang operasi penangkapan rawai tuna, terutama waktu mulai tebar pancing, dan perolehan hasil tangkapan madidihang di Samudra Hindia.

\section{BAHAN DAN METODE Pengumpulan Data}

Pemantau ilmiah melakukan pengumpulan dara dari Agustus 2005 hingga Juni 2014 di atas kapal rawai tuna Indonesia yang menangkap ikan di Samudra Hindia. Pemantau ilmiah mencatat waktu mulai tebar pancing, hasil tangkapan madidihang, total pancing yang digunakan dan lokasi yang diperoleh dari Global Positioning System (GPS) setiap hari selama trip penangkapan. Lokasi armada rawai tuna yang disampling berada antara $9^{\circ}-16^{\circ} \mathrm{LS}$ hingga $109^{\circ}$ $120^{\circ} \mathrm{BT}$ (Gambar 1). Waktu tebar pancing (setting) dikelompokkan setiap satu jam. Nilai laju tangkap diperoleh dengan menghitung proporsi antara hasil tangkapan madidihang pada satu operasi tangkapan dengan total mata pancing yang digunakan pada saat operasi penangkapan tersebut dikalikan 100.

Data fase bulan pada saat operasi penangkapan diperoleh dari National Aeronautics and Space Administration (NASA) (Espenak, 2015). Waktu pada saat operasi penangkapan kemudian dikelompokkan berdasarkan fase bulan perbani awal, purnama, perbani akhir dan bulan baru. Jumlah hari pada saat purnama dan bulan baru dihitung pada saat puncak purnama dan bulan baru \pm 3 hari. Sedangkan hari diantara kedua fase bulan tersebut dikelompokkan ke dalam fase bulan perbani awal dan perbani akhir. Kemudian waktu mulai tebar pancing dan nilai laju tangkap madidihang disortir dan dikelompokkan pada masing-masing fase bulan. 


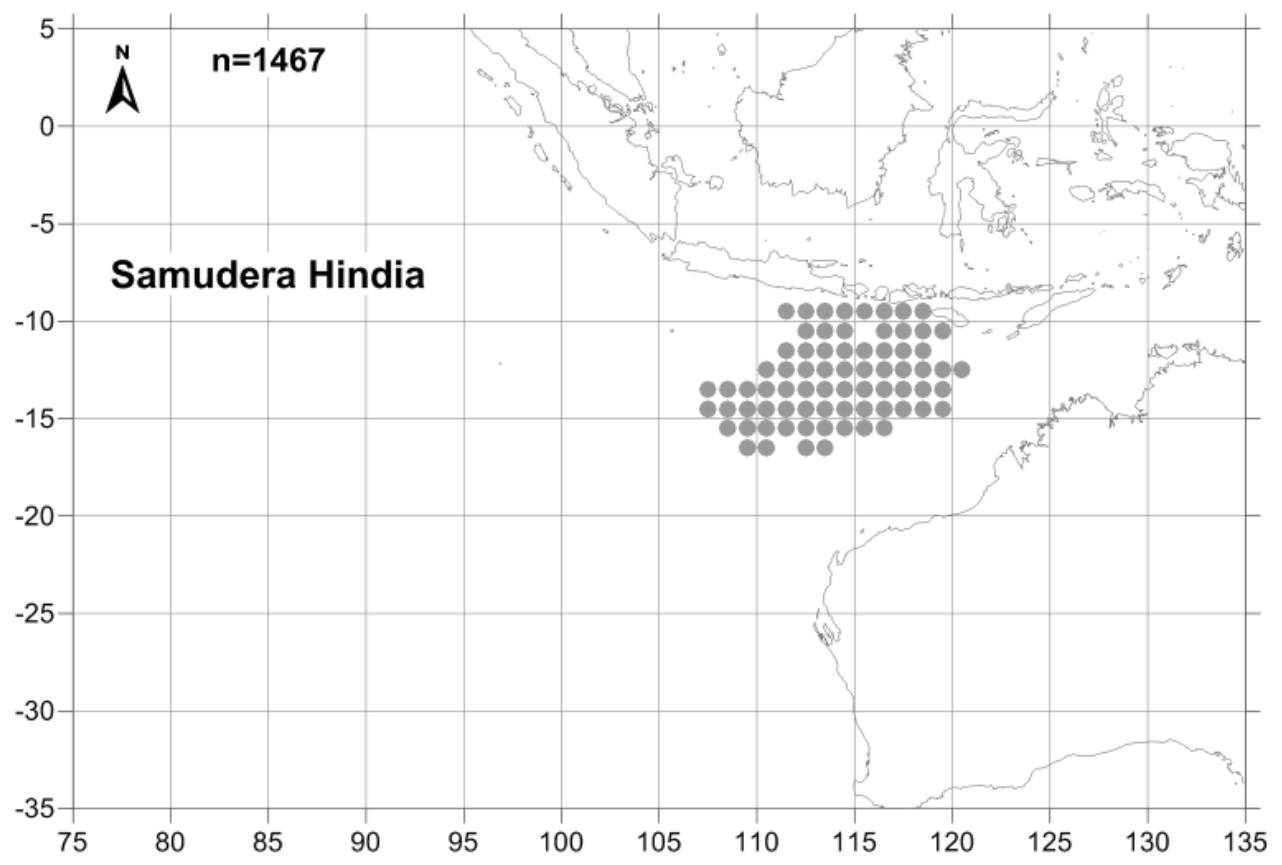

Gambar 1. Daerah penangkapan ikan dari armada rawai tuna dalam penelitian ini. Figure 1. Fishing ground of tuna longline vessels in this study.

\section{Analisis Data}

Analisis data menggunakan Anova satu arah untuk mengetahui pengaruh fase bulan terhadap waktu mulai tebar pancing dan laju tangkap madidihang. Hipotesis yang digunakan untuk mengetahui pengaruh fase bulan terhadap waktu mulai tebar pancing adalah:

$H_{0}$ : Tidak ada pengaruh fase bulan terhadap waktu mulai tebar pancing.

$H_{a}$ : Ada pengaruh fase bulan terhadap waktu mulai tebar pancing.

Sedangkan hipotesis yang digunakan untuk mengetahui pengaruh fase bulan terhadap laju tangkap madidihang adalah:

$H_{0}$ : Tidak ada pengaruh fase bulan terhadap laju tangkap madidihang.

$H_{a}$ : Ada pengaruh fase bulan terhadap laju tangkap madidihang.

Jika analisis anova satu arah menunjukkan perbedaan yang nyata, dilanjutkan dengan uji Tukey untuk mengetahui letak perbedaan tersebut (McDonald, 2014). Seluruh analisis dalam penelitian ini dilakukan menggunakan SPSS Statistics 20.

\section{HASIL DAN BAHASAN Hasil}

Total sebanyak 60 trip dan 1.467 hari operasi penangkapan armada rawai tuna dilakukan dalam penelitian ini. Selama operasi penangkapan tersebut, sebanyak 370 kali dilakukan pada saat perbani awal, 350 kali saat purnama, 393 kali saat perbani akhir dan 354 kali saat bulan baru. Secara umum, waktu mulai tebar pancing armada rawai tuna di Samudra Hindia dilakukan pada pagi hari. Sebanyak 1.269 hari operasi (86,5\%) armada rawai tuna melakukan tebar pancing mulai pukul 5:00 - 9:00 pagi hari dan yang tertinggi terjadi pada pukul 6:00 dengan 575 kali. Sedangkan waktu mulai tebar pancing yang dilakukan pada malam hingga dini hari (18:00 - 3:00) hanya dilakukan 53 kali atau kurang dari $1 \%$ dari total operasi penangkapan (Gambar 2).

Analisis statistik anova satu arah menunjukkan bahwa terdapat pengaruh yang nyata pada fase bulan terhadap waktu mulai tebar pancing $(p<0,05)$. Selanjutnya, uji Tukey menunjukkan bahwa waktu mulai tebar pancing pada saat purnama pada pukul 9:00 pagi hari dan ini lebih lambat sekitar 2 jam dari pada waktu mulai tebar pancing pada ketiga fase bulan lainnya yaitu pada pukul 7:00 pagi hari, yang tidak berbeda nyata $(p>0,05)$ (Gambar 3$)$.

Sebanyak 1.912 ikan madidihang tertangkap selama operasi penangkapan dengan mata pancing berjumlah 1.797 .061 buah. Hal ini berarti rata-rata nilai laju tangkap madidihang sebesar 0,11 ekor /100 mata pancing atau dinyatakan dengan hook rate sebesar 0,11 . Uji statistik anova satu arah menunjukkan perbedaan yang nyata antar fase bulan terhadap laju tangkap madidihang $(p<0,05)$. 
Selanjutnya, dengan uji Tukey menunjukkan bahwa laju tangkap pada saat bulan baru dan perbani awal sebanyak 0,13 ekor/100 mata pancing. Nilai laju tangkap ini lebih besar 0,04 ekor/100 mata pancing dibandingkan nilai laju tangkap pada saat purnama dan perbani akhir yang hanya mendapatkan 0,09 ekor/ 100 mata pancing (Gambar 4).

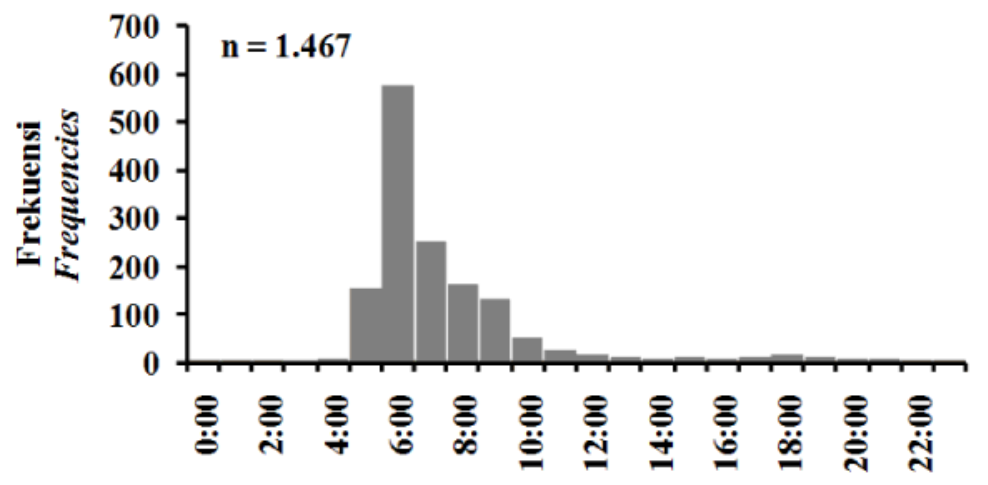

Waktu mulai tebar pancing

Set time start

Gambar 2. Waktu mulai tebar pancing armada rawai tuna di Samudra Hindia berbasis di Benoa Bali.

Figure 2. Setting time start for tuna longline in Indian Ocean base in Benoa Bali.

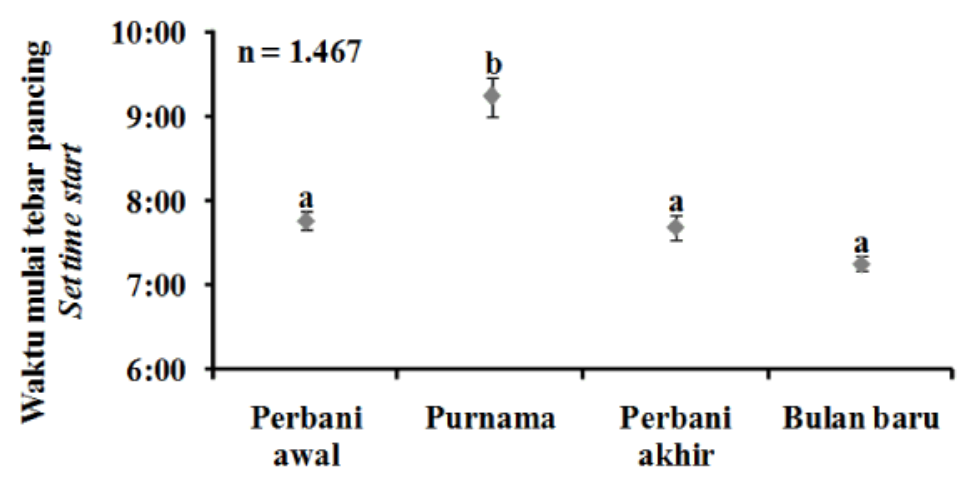

Fase bulan

Lunar phase

Gambar 3. Waktu mulai tebar pancing armada rawai tuna pada tiap-tiap fase bulan. Huruf yang berbeda menunjukkan adanya perbedaan yang nyata secara statistik.

Figure 3. Setting time of tuna longline for each lunar phase. Different letters show significantly different statistically

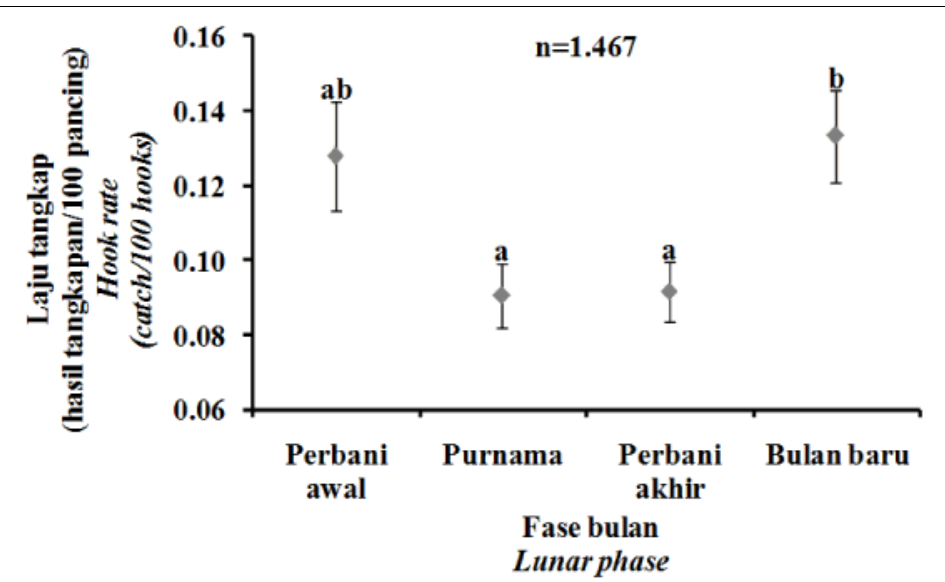

Gambar 4. Laju tangkap madidihang ( $T$. albacares) tertangkap rawai tuna pada tiap-tiap fase bulan. Huruf yang berbeda menunjukkan adanya perbedaan yang nyata secara statistik.

Figure 4. Hook rate of yellowfin tuna (T. albacares) caught by tuna long line for each lunar phase. Different letters show significantly different statistically. 


\section{Bahasan}

Secara umum, waktu mulai tebar pancing armada rawai tuna di Samudera Hindia yang berasal dari Benoa, Bali dilakukan pada pagi hari antara pukul 5:00 - 9:00 dan terbanyak dilakukan pada pukul 6:00. Waktu mulai tebar pancing ini hampir sama dengan yang dilakukan armada rawai tuna di perairan Samudra Pasifik. Di lokasi tersebut armada rawai tuna juga melakukan tebar pancing pada pagi hari antara pukul 4:00 - 8:00. Menurut Beverly et al. (2003), aktivitas tebar pancing dilakukan pada pagi hari untuk menghindari umpan dimakan oleh cumi-cumi dan spesies ikan lain yang melakukan perburuan makanan pada malam hari (night feeders). Hal ini juga terkait dengan kebiasaan ikan madidihang cenderung mencari makan pada pagi hari. Dengan tebar pancing pada pagi hari memungkinkan umpan dapat terlihat pada siang hari pada saat madidihang melakukan migrasi vertical (Barata et al., 2011; Brill et al., 1999). Pola migrasi ini memperbesar peluang madidihang untuk memakan umpan yang dipasang pada rawaituna (Block, et al., 1997; Cayre \& Marsac, 1993).

Fase bulan diketahui telah mempengaruhi operasi penangkapan armada rawai tuna untuk mendapatkan hasil tangkapan yang optimal (Poisson et al., 2010; Sajeevan \& Rajashree et al., 2012). Hasil analisis menunjukkan bahwa fase bulan dijadikan pertimbangan waktu mulai tebar pancing armada rawai tuna. Pada saat purnama, waktu tebar pancing dimulai pada pukul 9:00 atau 2 jam lebih lambat dari ketiga fase bulan lainnya yaitu dilakukan pukul 7:00. Berdasarkan wawancara dengan kapten kapal, waktu tebar pancing lebih lambat pada saat purnama dikarenakan pada malam hari umpan ikan seperti lemuru masih terlihat kilauannya karena pancaran sinar dari bulan, sehingga tidak mengurangi performa umpan dalam menarik perhatian ikan tuna.

Hasil analisis Barata (2011) menyatakan bahwa pada saat purnama, aktivitas tebar pancing dimulai pada sore hingga malam hari dan pada saat bulan baru aktivitas tebar pancing dilakukan pada pagi hingga siang hari. Hal ini berbeda dari penelitian ini yang menunjukkan bahwa mayoritas aktivitas tebar pancing dimulai pada pagi hari dari pukul 5:00 - 9:00. Meskipun secara statistik terdapat perbedaan pada saat fase bulan purnama, aktivitas tebar pancing pada fase bulan tersebut masih dilakukan pada pagi hari yaitu pukul 9:00. Waktu tebar ini hanya lebih lambat 2 jam dari ketiga fase bulan lainnya yang melakukan aktivitas tebar pancing pada pukul 7:00.

Hasil penelitian juga membuktikan bahwa fase bulan mempengaruhi hasil tangkapan madidihang di
Samudra Hindia. Laju tangkap madidihang pada saat fase bulan baru dan perbani awal tercatat 0,13 ekor/ 100 mata pancing. Nilai ini lebih besar 0,04 ekor/100 mata pancing dibandingkan dengan laju tangkap rawai tuna ditebar pada saat fase bulan purnama dan perbani akhir yang hanya sebesar 0,09 ekor/100 mata pancing. Berdasarkan wawancara dengan nakhoda, laju tangkap yang tinggi pada saat bulan baru dikarenakan umpan lebih terlihat karena adanya cahaya dari bulan, sehingga peluang umpan untuk dimakan ikan target menjadi lebih besar. Hal ini sama dengan yang terjadi pada hasil tangkapan ikan pedang (Xiphias gladius) (Akyol, 2013) dan albakor (Thunnus alalunga) (Akyol \& Ceyhan, 2012) di Samudra Atlantik. Hasil tangkapan kedua spesies tersebut juga lebih banyak saat operasi penangkapan dilakukan pada saat fase bulan baru.

\section{KESIMPULAN}

Armada rawai tuna yang berbasis di Benoa Bali yang melakukan operasi penangkapan di Samudra Hindia Bagian Timur melakukan tebar pancing pada pagi hari antara pukul 5:00-9:00. Pada saat purnama tebar pancing dilakukan pada pukul 9:00 atau 2 jam lebih lambat daripada saat fase bulan lainnya. Besaran nilai laju tangkap ikan madidihang tertangkap rawai tuna ditebar pada saat fase bulan baru lebih tinggi dibandingkan pada saat purnama dan perbani. Dengan demikian, untuk kapten kapal tetap disarankan untuk melakukan waktu mulai tebar pancing pada pagi hari pukul 7:00. Hal ini perlu dilakukan untuk memperoleh hasil yang optimal karena madidihang aktif mencari makan dan melakukan migrasi vertikal pada pagi hari.

\section{PERSANTUNAN}

Penelitian ini dibiayai dari kerjasama Pusat Penelitian Pengelolaan Perikanan dan Konservasi Sumber Daya Ikan (P4KSI) dengan Australian Centre for International Agricultural Research (ACIAR) pada tahun 2005-2009, DIPA kegiatan riset Balai Penelitian Perikanan Laut (BPPL) pada tahun 2010-2011 dan DIPA kegiatan riset Loka Penelitian Perikanan Tuna (LP2T) pada tahun 2012-2014. Peneliti mengucapkan terima kasih kepada para pemantau ilmiah di Loka Penelitian Perikanan Tuna (LP2T) Benoa yang telah membantu dalam proses pengumpulan data penelitian ini.

\section{DAFTAR PUSTAKA}

Akyol, O. (2013). The influence of the moon phase on the CPUEs of swordfish gillnet fishery in the Aegean Sea, Turkey. Turkish Journal Fisheries 
and Aquatic Sciences. 13, 355-358. DOI: 10.4194/ 1303-2712-v13_2_18.

Akyol, O., \& Ceyhan, T. (2012). Moon phase's influence on CPUE of Turkish albacore gillnet fishery. Collect. Vol. Sci. Pap. ICCAT. 68(2), 499502.

Barata, A., Bahtiar, A., \& Novianto, D. (2011). Sebaran ikan tuna berdasarkan suhu dan kedalaman di Samudera Hindia. J. IImu. Kel. 16(3), 165-170.

Barata, A., Bahtiar, A., \& Hartaty, H. (2011). Pengaruh perbedaan umpan dan waktu setting rawai tuna terhadap hasil tangkapan tuna di Samudera Hindia. J. Lit. Perik. Ind. 17(2), 133-138.

Beverly, S., Chapman, L., \& Sokimi, W. 2003. Horizontal longline fishing methods and techniques: A manual for fishermen (p. 130). Noumea, New Caledonia: Secretariat of the Pacific Community.

Block, B.A., Keen, J.E., Castillo, B., Dewar, H., Freund, E.V., Marcinek, D.J., Brill, R.W., \& Farwell, C. (1997). Environmental preferences of yellowfin tuna (Thunnus albacares) at the northern extent of its range. Marine Biology. 130, 119-132.

Brill, R.W., Block, B.A., Boggs, C.H., Bigelow, K.A., Freund, E.V., \& Marcinek, D.J. (1999). Horizontal movements and depth distribution of large adult yellowfin tuna (Thunnus albacares) near the Hawaiian Islands, recorded using ultrasonic telemetry: Implications for the physiological ecology of pelagic fishes. Mar. Biol. 133, 395-408.

Cayre, P., \& Marsac, F. (1993). Modelling the yellowfin tuna (Thunnus albacares) vertical distribution using sonic tagging results and local environmental parameters. Aquatic Living Resources. 6, 1-14.

Colette, H.B. \& Nauen, C.E. (1983). FAO species catalogue. Vol. 2. Scombrids of the world. An Annonated and illustrated catalogue of tunas, mackerels, bonitos, and related species known to date (p. 137). Rome, Italy: FAO Press.

Das, D., Pal, S., Bhaumik, U., Paria, T., Mazumdar, D., \& Pal, S. (2015). The optimum fishing day is based on moon. International Journal of Fisheries and Aquatic Studies, 2(4), 304-309.

Direktorat Jenderal Perikanan Tangkap (DJPT). (2014). Rencana Aksi Nasional; Rencana pengelolaan perikanan tuna, cakalang dan tongkol (p. 126). Jakarta: Direktorat Jenderal Perikanan Tangkap, Kementerian Kelautan dan Perikanan.

Espenak, F. (2015). NASA Eclipse Web Site. [http:/ /eclipse.gsfc.nasa.gov/ SKYCAL/ SKYCAL.html?cal=2015\#skycal]. Accessed 10 August 2015.

Food and Agricultural Organization (FAO). (2012). The State of World Fisheries and Aquaculture 2012 (p. 230). Rome, Italy: FAO Fisheries and Aquaculture Department.

Hamilton, A., Lewis, A., McCoy, M.A., Havice, E. \& Campling, L. (2011). Market and industry dynamics in the global tuna supply chain (p. 396). Honiara, Solomon Islands: The Pacific Islands Forum Fisheries Agency.

Jatmiko, I., Nugraha, B., \& Satria, F. (2015). Capaian perkembangan program pemantau pada perikanan rawai tuna di Indonesia. Marine Fisheries. 6(1), 19.

Keputusan Menteri Kelautan dan Perikanan. (2011). Kepmen KP No. KEP. 45/MEN/2011 tentang Estimasi Potensi Sumberdaya Ikan di Wilayah Pengelolaan Perikanan Negara Republik Indonesia (p. 12). Jakarta: Kementerian Kelautan dan Perikanan.

Lehodey, P. (2001). The pelagic ecosystem of the tropical Pacific Ocean: dynamic spatial modelling and biological consequences of ENSO. Progr. Oceanogr., 49, 439-468

King, M. (2010). Fisheries biology, assessment and management, Second Edition (p. 381). Oxford, England: Blackwell Publising Ltd.

McDonald, J.H. (2014) Handbook of biological statistics, Third Edition (p. 299). Maryland, USA: Sparky House Publishing.

Mohan, M., \& Kunhikoya, K.K. (1987). Baitfish and tuna catches at Minicoy Island (Lakashadweep) in relation to lunar cycle during 1983-1984 seasons. Indian Journal Fisheries. 34, 355-358.

Nugraha, B., \& Setyadji, B. (2013). Kebijakan pengelolaan hasil tangkapan sampingan tuna longline di Samudera Hindia. J. Kebijak. Perik. Ind. 5(2), 67-71. 
Poisson, F., Gaertner, J.C., Taquet, M., Durbec, J.P., \& Bigelow, K. (2010). Effects of lunar cycle and fishing operations on longline-caught pelagic fish: fishing performance, capture time, and survival of fish. Fishery Bulletin. 108, 268-281.

Sadiyah, L., \& Prisantoso, B.I. (2011). Fishing strategy of the Indonesian tuna longliners in Indian Ocean. Indonesian Fisheries Research Journal. $17(1), 29-35$.
Sajeevan, M.K., \& Rajashree, B.S. (2012). Diversity, distribution and abundance of oceanic resources around Andaman and Nicobar Islands. Indian J. Fish. 59(2), 63-67.

Soepriyono, Y. (2009). Teknik dan manajemen penangkapan tuna melalui metode longline (p. 78). Denpasar, Bali: Penerbit Bilas Utama.

Wudianto \& Nikijuluw, V.P.H. (2004). Guide to invest on fisheries in Indonesia (p. 17). Jakarta, Indonesia: Kementerian Kelautan dan Perikanan. 
Lampiran 1. Uji statistik Anova satu arah dan tes Tukey waktu mulai tebar pancing pada beberapa fase bulan.

Appendix 1. One-way Anova statistics and Tukey test of set time start at different lunar phases.

Tests of Between-Subjects Effects

Dependent Variable: WaktuSet

\begin{tabular}{|l|r|r|r|r|r|}
\hline Source & \multicolumn{1}{|c|}{$\begin{array}{c}\text { Type III Sum } \\
\text { of Squares }\end{array}$} & df & Mean Square & \multicolumn{1}{c|}{ F } & \multicolumn{1}{c|}{ Sig. } \\
\hline Corrected Model & $790.243^{\mathrm{a}}$ & 3 & 263.414 & 29.881 & .000 \\
Intercept & 93305.034 & 1 & 93305.034 & 10584.264 & .000 \\
Phase & 790.243 & 3 & 263.414 & 29.881 & .000 \\
Error & 12897.001 & 1463 & 8.815 & & \\
Total & 106860.754 & 1467 & & & \\
Corrected Total & 13687.243 & 1466 & & & \\
\hline
\end{tabular}

Tukey HSDa,b,c

\section{WaktuSet}

\begin{tabular}{|l|r|r|r|}
\hline & \multirow{2}{*}{ Phase } & \multicolumn{2}{|c|}{ Subset } \\
\cline { 3 - 4 } & $\mathrm{N}$ & 1 & \multicolumn{1}{|c|}{2} \\
\hline Bulan_baru & 354 & 7.2559698682 & \\
Perbani_akhi & & 2 & \\
r & 393 & 7.6804502403 & \\
Perbani_awal & 370 & 7.7614256756 & \\
Purnama & & 1 & \\
& 350 & & 9.2357182539 \\
\hline Sig. & & .098 & 1.000 \\
\hline
\end{tabular}

Lampiran 2. Uji statistik Anova satu arah dan tes Tukey laju tangkap madidihang pada beberapa fase bulan. Appendix 2. One-way Anova statistics and Tukey test of set time start at different lunar phases.

Dependent Variable: hr_yft

Tests of Between-Subjects Effects

\begin{tabular}{|l|r|r|r|r|r|}
\hline Source & $\begin{array}{c}\text { Type III Sum } \\
\text { of Squares }\end{array}$ & \multicolumn{1}{c|}{ df } & Mean Square & \multicolumn{1}{c|}{ F } & \multicolumn{1}{c|}{ Sig. } \\
\hline Corrected Model & $.577^{\mathrm{a}}$ & 3 & .192 & 4.200 & .006 \\
Intercept & 17.955 & 1 & 17.955 & 392.332 & .000 \\
Phase & .577 & 3 & .192 & 4.200 & .006 \\
Error & 66.954 & 1463 & .046 & & \\
Total & 85.435 & 1467 & & & \\
Corrected Total & 67.531 & 1466 & & & \\
\hline
\end{tabular}

Tukey HSDa,b,c

$$
\text { hr_yft }
$$

\begin{tabular}{|l|r|r|r|}
\hline & \multirow{2}{*}{ Phase } & \multicolumn{2}{|c|}{ Subset } \\
\cline { 3 - 4 } & \multicolumn{1}{|c|}{ N } & \multicolumn{1}{c|}{2} \\
\hline Purnama & 350 & .0905 & \\
Perbani_akhi & 393 & .0914 & \\
r & & & \\
Perbani_awa & 370 & .1277 & .1277 \\
l & 354 & & .1333 \\
Bulan_baru & & .087 & .985 \\
\hline Sig. & &
\end{tabular}

